\title{
Ketahanan mental dan kecerdasan emosi dalam kalangan atlet berpasukan dan individu
}

\author{
Nurnadhira Nazri \& Norlena Salamuddin \\ Fakulti Pendidikan, Universiti Kebangsaan Malaysia \\ Jurnal Sains Sukan dan Pendidikan Jasmani 8(2): 10-23, Received: 15 September 2019, \\ Accepted: 1 Disember 2019
}

DOI: https://doi.org/10.37134/jsspj.vol8.2.2.2019

\begin{abstract}
Abstrak
Kajian ini dijalankan bertujuan untuk mengkaji hubungan ketahanan mental dan kecerdasan emosi terhadap atlet berpasukan dan individu. Borang soal selidik Mental Toughness Questionnaire 48 (MTQ48) diguna pakai untuk mengukur empat konstruk kajian ketahanan mental, iaitu keyakinan diri, komitmen, cabaran dan kawalan diri. Manakala Mayer-Salovey-Caruso Emotional Intelligence Test (MSCEIT) diguna pakai untuk mengukur 4 konstruk kajian kecerdasan emosi, iaitu persepsi emosi, penggunaan emosi, kefahaman emosi dan pengurusan emosi. Seramai 49 atlet dipilih sebagai sampel kajian dengan atlet yang menjadi sampel sekurang-kurangnya mewakili peringkat kebangsaan dan antarabangsa dalam bidang sukan yang diceburi. Hasil kajian mendapati nilai min yang tertinggi bagi konstruk ketahanan mental adalah keyakinan diri (min=3.76). Manakala bagi konstruk kecerdasan emosi, pengurusan emosi $(\min =3.73)$ mempunyai nilai min tertinggi. Namun begitu, kajian menunjukkan terdapat hubungan antara ketahanan mental dan kecerdasan emosi dalam kalangan atlet secara kesuluruhannya $(\mathrm{r}=0.472, \mathrm{p}<0.05)$. Seterusnya, kajian menunjukkan tidak terdapat hubungan antara ketahanan mental dan kecerdasan emosi dalam kalangan atlet berpasukan $(\mathrm{r}=0.245, \mathrm{p}>0.05)$. Walaubagaimanapun, hasil kajian mendapati konstruk ketahanan mental dan kecerdasan emosi $(\mathrm{r}=0.623, \mathrm{p}<0.05)$ mempunyai hubungan yang signifikan terhadap atlet individu. Ini menunjukkan bahawa dapatan kajian ini memberi kesan kepada jurulatih, ahli psikologi dan atlet sendi dalam memahami pentingnya aspek piskologi dalam mencapai matlamat mereka.
\end{abstract}

Katakunci: ketahanan mental, kecerdasan emosi, atlet berpasukan.

\section{Mental toughness and emotional intelligence among team and individual athlete}

\begin{abstract}
This study aimed to investigate the relationship between mental toughness and emotional intelligence among individual and team athletes in UKM. Mental Toughness Questionnaire 48 (MTQ48) were used to measure four constructs of mental toughness which are confidence, commitment, challenge and self-control. While MayerSalovey-Caruso Emotional Intelligence Test (MSCEIT) were used to measure four constructs of emotional intelligence, include perceiving emotion, using emotion, understanding emotion and managing emotion. A total of 49 athletes were selected as sample studies with athletes who were sampled at least representing national and international level in the field of sports. The results showed that the highest mean value of the mental toughness construct was self confidence (mean = 3.76). While for the construct of emotional intelligence, managing emotion (mean $=3.73)$ has the highest mean value. However, the study showed that there is correlation between mental toughness and emotional intelligence among athletes $(r=0.472, p<0.05)$. Next, there is no correlation between mental toughness and emotional intelligence among team athletes $(r=0.245, p>0.05)$. However, the findings showed that mental toughness and emotional intelligence $(r=0.623, p<0.05)$ had significant relationships among individual athletes. This shows that the findings of this study affect coaches, psychologists and athletes in understanding the importance of psychology to achieve their goals.
\end{abstract}


Keywords: mental toughness, emotional intelligence, team athletes.

\section{PENGENALAN}

Pada masa kini, sukan merupakan salah satu cabang untuk meningkatkan ekonomi negara agar terus maju di seluruh dunia. Sehubungan dengan itu, atlet adalah penggerak utama dalam mencapai kejayaan dan mengharumkan nama negara. Prestasi dan kualiti atlet untuk mencapai kejayaan dalam arena ini semakin merosot disebabkan faktor ketahanan mental dan kecerdasan emosi atlet. Pendekatan ahli psikologi sukan dalam mengekalkan ketahanan mental dan kecerdasan emosi atlet perlulah dititikberatkan. Dengan mempunyai atlet yang sihat dari segi rohani dan jasmani, ketahanan mental dan kecerdasan emosi dapat meningkatkan konsentrasi dan prestasi atlet.

Perkembangan mental atlet telah menjadi tumpuan utama bagi banyak pasukan dan organisasi di seluruh dunia (Mahoney, Gucciardi, Ntoumanis \& Mallett 2014). Menurut Cowden (2016) atlet memerlukan ketahanan mental yang kuat dalam menghadapi cabaran dan mengekalkan kawalan emosi serta tingkah laku. Kesedaran atlet terhadap kecerdasan emosi adalah mampu untuk mengenali diri sendiri dan atlet lain serta mampu mengawal emosi dengan lebih baik. Kajian daripada Fridlund Dunton, Schneider, Graham dan Cooper (2006) menyatakan bahawa atlet yang mempunyai emosi yang baik, dapat mengurangkan risiko tekanan dan kebimbangan serta memberi kesan yang positif dari aspek psikomotor dan kognitif. Dengan ini, atlet memerlukan ketahanan mental dan kecerdasan emosi yang kuat dalam menghadapi cabaran dan mengekalkan kawalan emosi serta tingkah laku. Dalam aspek sukan terdapat faktor psikologi yang penting, iaitu cara jurulatih mendorong atlet dalam meningkatkan prestasi sukan semasa latihan dan ketika pertandingan (Institut Sukan Negara Malaysia, 2015).

Pengkaji juga mendapati bahawa terdapat beberapa faktor utama yang menyebabkan berlakunya masalah dan tingkah laku atlet ketika pertandingan. Tingkah laku atlet sering dipertikai apabila mereka berada di padang dan mempunyai unsur negatif ketika pertandingan. Kurangnya sikap profesional dalam kalangan atlet ketika pertandingan menyebabkan beberapa tingkah laku negatif timbul seperti keganasan di dalam sukan (Fruchart \& Rulence-Paques 2014; Mullet 2012; Hashim 2007) dan ini mengakibatkan prestasi atlet menurun (Krishnaveni \& Shahin 2014). Kajian daripada Darvishi, Marati dan Amirpour (2015) menyatakan bahawa kecerdasan emosi dikaitkan dengan ketahanan mental. Hal ini demikian kerana dengan kemahiran mental yang baik, pengurusan emosi dan prestasi atlet dapat ditingkatkan. Pengaruh emosi dalam sukan adalah penting ketika pertandingan walaupun sukan boleh dipraktikkan untuk keseronokan (Sit \& Lindner 2005). Selain itu, isu berkenaan S Komalam Shally yang digugurkan daripada menyertai Sukan Sea Kuala Lumpur 2017 adalah kerana masalah disiplin dan tidak mampu mengawal emosi ketika pertandingan (Zaid, 2017). Hal ini menunjukkan atlet juga mengalami tekanan yang tinggi ketika mereka berusaha mencapai prestasi yang tinggi (Neil, Hanton, Mellalieu \& Fletcher 2011). Tekanan dan emosi yang dialami oleh atlet lebih tinggi apabila matlamat yang sangat bernilai dipertaruhkan.

Pengkaji akan menggunakan kaedah soal selidik di mana setiap sampel kajian akan menerima dan melengkapkan borang Mental Toughness Questionnaire (MTQ48) dan Mayer-Salovey-Caruso Emotional Intelligence Test dan selepas dikumpul, data tersebut akan diproses menggunakan analisis korelasi Pearson. Seterusnya, kajian ini dibuat untuk mengetahui sejauh mana hubungan tahap ketahanan mental dan kecerdasan emosi atlet.

Oleh itu, kajian psikologi ini adalah perlu kerana setiap atlet memerlukan ketahanan mental dan kecerdasan emosi yang tinggi untuk mengatasi sesuatu keadaan yang tegang dalam keadaan tenang dan positif. Secara keseluruhannya, diharapkan kajian ini dapat mencapai objektif kajian dan mampu untuk menghadirkan satu keputusan yang dapat membantu banyak pihak dalam menangani masalah ketahanan mental dan kecerdasan emosi ini serta pembinaan psikologi di kalangan atlet adalah perlu bagi pembinaan tingkah laku yang positif.

\section{Objektif kajian}

Objektif utama kajian dijalankan untuk:- 
1. Mengenal pasti tahap ketahanan mental dan kecerdasan emosi dalam kalangan atlet berpasukan dan individu.

2. Mengenal pasti hubungan antara tahap ketahanan mental dan kecerdasan emosi dalam kalangan atlet berpasukan dan individu.

\section{Tinjauan literatur}

Perkembangan mental atlet telah menjadi tumpuan utama bagi banyak pasukan dan organisasi di seluruh dunia (Mahoney et al. 2014). Atlet memerlukan ketahanan mental yang kuat dalam menghadapi cabaran dan mengekalkan kawalan emosi serta tingkah laku. Darvishi et al. (2015) menyatakan bahawa kecerdasan emosi dapat meramalkan tekanan dan dikaitkan dengan kesihatan dan ketahanan mental. Kecerdasan emosi dan ketahanan mental memainkan peranan kalangan atlet. Hal ini demikian kerana kecerdasan emosi yang lebih tinggi adalah dikaitkan dengan ketahanan mental yang baik dalam diri atlet.

Ketahanan mental didefinisikan sebagai keteguhan dan keyakinan dalam mencapai matlamat walaupun menghadapi tekanan dan kesusahan (Middleton, Marsh, Martin, Richards, \& Clark Perry, 2005). Sikap emosi dan pemikiran adalah ketahanan mental yang seharusnya ada dalam setiap diri atlet kerana dapat mempengaruhi tindak balas dalam menghadapi cabaran dan tekanan untuk mencapai matlamat masing-masing. Para pengkaji daripada luar negara berpendapat bahawa ketahanan mental adalah penting dan penyumbang kepada prestasi yang cemerlang (Gould et al. 2012; Krane \& William, 2006; Bull et al. 2005) dan ketahanan mental dapat membantu atlet dalam meningkatkan pencapaian dan mengatasi masalah dengan mudah. Kajian daripada Hany Mahmoud Abou-Bakri dan Mostafa (2016) menyatakan bahawa ketahanan mental pada setiap atlet menyumbang kepada 50\% kejayaan semasa pertandingan. Ketahanan mental dapat membantu atlet dalam meningkatkan pencapaian dan mengatasi masalah dengan mudah.

Empat aspek untuk mengenal pasti tahap ketahanan mental bagi setiap atlet, iaitu keyakinan diri (self confidence), komitmen (commitment), cabaran (challenge) dan kawalan diri (self-control). Keyakinan diri adalah penting dalam kalangan atlet untuk membangunkan semangat dalam sesebuah pasukan dan komitmen adalah salah satu sifat yang perlu ada dalam setiap diri atlet dalam memperbaiki kelemahan dan menjadikannya sebagai kekuatan (Coulter et al. 2010). Sehubungan dengan itu, cabaran bukanlah sesuatu ancaman tetapi dijadikan sebagai peluang dan kawalan diri dalam pertandingan adalah amat penting untuk mengelakkan berlakunya perkara negatif(Nur Dalilah, 2016). Dengan adanya tahap ketahanan mental yang tinggi, atlet akan lebih bijak dalam mengawal stress, tekanan dan mempunyai keupayaan untuk mengatasi rasa bersalah jika gagal atau melakukan kesilapan dalam pertandingan.

Seterusnya, Lane dan Thelwell (2009) pula mentakrifkan kecerdasan emosi sebagai tingkah laku yang diingini dan mempunyai psikologi yang berlainan. Mayer, Salovey dan Caruso (2004) menyatakan bahawa kecerdasan emosi adalah keupayaan individu untuk memantau, membezakan dan menggunakan maklumat untuk bertindak kepada sesuatu situasi. Sehubungan dengan itu, kecerdasan emosi dikaitkan dengan pengetahuan tentang diri sendiri dan orang lain, hubungan dengan orang lain, dan penyesuaian kepada persekitaran, yang diperlukan untuk memenuhi permintaan sosial (Darvishi et al. 2015). Dengan adanya tahap kecerdasan emosi yang tinggi, atlet berkemampuan untuk memotivasikan diri sendiri dan orang lain serta menangani masalah yang sering berlaku dalam kalangan atlet ketika bersukan. Kajian luar negara dijalankan oleh Darvishi et al. (2015) menyatakan bahawa atlet perlu mengekalkan kecerdasan emosi sebelum, semasa dan selepas pertandingan agar tidak terdapat perkara yang tidak diingini berlaku seperti pergaduhan.

Sehubungan dengan itu, terdapat empat faktor kecerdasan emosi daripada model Goleman (1995), iaitu persepsi emosi (perceiving emotion), penggunaan emosi (using emotion), kefahaman emosi (understanding emotion) dan pengurusan emosi (managing emotion). Brackett, Rivers, Shiffman, Lerner dan Salovey (2006) menyatakan persepsi emosi adalah keupayaan untuk mengenal pasti emosi dalam diri sendiri dan orang sekeliling. Penggunaan emosi adalah keupayaan atlet untuk menjana, menggunakan, dan merasakan emosi yang diperlukan untuk menyampaikan perasaan atau menggunakannya dalam proses kognitif yang lain. Keupayaan untuk pemikiran yang mencerminkan keupayaan untuk menganalisis emosi dan untuk memahami bagaimana emosi digunakan dengan sesama manusia yang lain adalah kefahaman emosi yang diperlukan oleh setiap atlet. Pengurusan emosi 
pula ditakrifkan sebagai kemampuan untuk menguruskan emosi dan emosi atlet lain (Fiori, Antonietti, Mikolajczak, Luminet, Hansenne \& Rossier, 2014).

Satu kajian telah dilakukan di luar negara untuk mengkaji perbezaan kecerdasan emosi dan ketahanan mental terhadap atlet yang berjaya dan tidak berjaya dalam liga karate lelaki Iran (Ranjbar, Gharayagh Zandi \& Fatemi, 2018). Kajian ini menunjukkan bahawa psikologi memberi kesan ke atas kejayaan seseorang atlet. Seterusnya, kajian daripada Kajbafnezhad, Ahadi, Heidarie, Askari dan Enayati (2011) menyatakan bahawa terdapat perbezaan antara pasukan dan sukan individu dari segi kemahiran mental. Dalam menjelaskan perbezaan ini, kemahiran mental dan emosi merupakan salah satu faktor penting dalam kejayaan atlet tetapi corak impaknya tidak sama bagi setiap atlet yang mempunyai tahap yang berbeza (amatur, sub elit, elit) dan jenis sukan (pasukan dan individu).

Kajian ini menggunakan dua teori untuk mengenal pasti tahap ketahanan mental dan kecerdasan emosi atlet berpasukan dan individu. Teori pertama yang digunakan untuk ketahanan mental adalah Teori Ketabahan (Hardiness) daripada Kobasa (1979) manakala teori kedua yang digunakan untuk kecerdasan emosi adalah Teori kecerdasan emosi (Emotional Intelligence) oleh Mayer dan Salovey (1990). Teori Hardiness merangkumi beberapa ciri-ciri keperibadian atlet termasuklah ciri-ciri ketahanan mental, iaitu keyakinan, komitmen, cabaran dan kawalan diri. Dengan ini, mempunyai sifat ketabahan lebih cenderung dalam menjadikan ketabahan (hardiness) sebagai satu motivasi untuk mengawal diri dengan baik dalam setiap keadaan yang dihadapi dan menjadi salah satu faktor kemampuan atlet ketika berada dalam situasi yang tertekan dan mencabar. Selain itu, teori kecerdasan emosi dibina adalah untuk mengkaji kemampuan emosi dalam setiap individu dan menjelaskan mekanisme kognitif dan emosi yang memproses maklumat emosi. kecerdasan emosi dan keberkesanannya pada setiap individu dapat dikaitkan dalam kejayaan dan meningkatkan keyakinan diri apabila terjadinya sesuatu perubahan.

Oleh itu, teori ini dapat merumuskan bahawa ketahanan mental dan kecerdasan emosi atlet bukan sahaja memainkan peranan yang penting semasa pertandingan tetapi juga diperlukan untuk membangunkan kareer atlet sukan yang berjaya. Kenyataan ini turut disokong oleh Cashmore (2002) yang menyatakan bahawa minda yang optimum dan rasional akan kekal sepanjang pertandingan jika atlet mempunyai ketahanan mental dan kecerdasan emosi yang baik. Justeru itu, ketahanan mental dan kecerdasan emosi memainkan peranan penting dalam meningkatkan prestasi atlet. Ini kerana dengan kemahiran mental yang baik, pengurusan emosi dan prestasi atlet dapat ditingkatkan. Pengaruh emosi dalam sukan adalah penting ketika pertandingan walaupun sukan boleh dipraktikkan untuk keseronokan.

\section{METODOLOGI}

\section{Rekabentuk Kajian}

Kajian yang dijalankan ini bersifat deskriptif menggunakan pendekatan tinjauan. Reka bentuk tinjauan dipilih kerana dalam kajian ini ianya menggunakan soal selidik (questionnaire) bagi mengumpulkan data. Data kajian telah dikumpul menerusi kaedah kuantitatif dengan menggunakan instrument soal selidik yang telah diubah suai serta disahkan kebolehpercayaannya.

\section{Instrumen Kajian}

Instrumen yang digunakan bagi ketahanan mental adalah Mental Toughness Questionnaire (MTQ48) diadaptasi daripada Clough et al. (2002) yang mengandungi 28 soalan. Terdapat empat dimensi bagi ketahanan mental, iaitu keyakinan diri, cabaran, kawalan diri dan komitmen.

Manakala Mayer-Salovey-Caruso Emotional Intelligence Test (MSCEIT) diadaptasi daripada Mayer, Salovey dan Caruso (2002) digunakan bagi kecerdasan emosi mengandungi 19 soalan. Terdapat empat dimensi bagi kecerdasan emosi, iaitu persepsi emosi (perceiving emotion), penggunaan emosi (using emotion), kefahaman emosi (understanding emotion) dan pengurusan emosi (managing emotion). 


\section{Responden Kajian}

Seramai 49 orang atlet dari Universiti Kebangsaan Malaysia (UKM) telah dipilih untuk menjadi responden dalam kajian ini. Sampel dipilih melalui kaedah persampelan purposif (purposive sampling), iaitu prosedur persampelan daripada sekumpulan responden yang mempunyai ciri-ciri dan tujuan khusus yang telah ditetapkan oleh pengkaji seperti tahap penglibatan. Hanya atlet peringkat kebangsaan dan antarabangsa dipilih untuk menjadi responden, iaitu 16 orang atlet peringkat antarabangsa dan 33 orang atlet peringkat kebangsaan. Daripada 49 orang atlet, seramai 35 atlet berpasukan dan 14 atlet individu. Responden merupakan pelajar daripada Universiti Kebangsaan Malaysia (UKM) yang mengikuti program Ijazah Sarjana Muda Pendidikan Sukan dan Rekreasi.

\section{Prosedur Pengumpulan Data}

Pada peringkat awal kajian, pengkaji telah menghubungi dan membuat surat rasmi kepada pengarah pusat sukan untuk mendapatkan populasi atlet kebangsaan dan antarabangsa. Tujuan kajian dinyatakan dalam surat permohonan untuk mendapatkan data atlet yang sedang berlatih di peringkat kebangsaan dan antarabangsa. Setelah mendapat data dan sampel, pengkaji mendapatkan pengesahan soal selidik daripada pakar bahasa dan pakar bidang agar setiap item yang digunakan mudah difahami oleh reponden. Seterusnya, menjalankan kajian rintis sebelum memberi responden sebenar menjawab.

Setelah kajian rintis selesai dijalankan dan dianalisis, pengkaji membuat temujanji dengan jurulatih untuk mendapatkan masa yang sesuai untuk mengedarkan borang soal selidik. Kesemua atlet dikumpulkan sebelum latihan dan diberikan penerangan ringkas tentang tujuan soal selidik serta maksud soalan pada setiap item. Tiada had masa diberikan kepada responden untuk menjawab kesemua soalan tersebut. Dengan ini, responden akan lebih tenang dalam menjawab soalan dan membaca soalan dengan teliti. Soal selidik dikumpulkan terus daripada responden selepas mereka selesai menjawab kesemua soalan.

\section{Kajian Rintis}

Kajian rintis dijalankan bagi menguji secara kecilan dengan tujuan untuk mengenal pasti kelemahan daripada instrumen kajian yang digunakan. Kesahan diperlukan daripada kajian agar kajian yang dilakukan dengan menggunakan ukuran yang tepat dan instrumen yang betul (Jackson, 2003). Kajian rintis dilakukan terhadap instrumen dalam kajian ini sebelum pengumpulan data sebenar dijalankan. Satu kajian rintis dijalankan terlebih dahulu untuk mengukuhkan ketepatan dan kestabilan instrumen yang digunakan.

Sebelum kajian rintis dijalankan, instrumen ini telah dinilai oleh pakar bahasa dan pakar bidang psikologi agar setiap item yang digunakan mudah difahami oleh responden. Seterusnya, kajian rintis dilakukan dengan mengedarkan borang soal selidik kepada 30 atlet Ijazah Sarjana Pengurusan Sukan, Fakulti Pendidikan, Universiti Kebangsaan Malaysia (UKM).

Data kajian rintis dianalisis dengan menggunakan Statistical Package for Social Sciences versi 22.0 untuk mendapatkan nilai pekali Cronbach's Alpha. Jadual 1 menunjukkan pekali saiz cronbach alpha yang digunakan untuk mengetahui sejauh mana instrumen dapat mengukur setiap dimensi yang diperlukan (Mohd Majid Konting, 2005).

Jadual 1:Pekali saiz Cronbach's Alpha

\begin{tabular}{cc}
\hline Alpha Coefficient Range & Kekuatan Hubungan \\
\hline$<0.6$ & Lemah \\
$0.6<0.7$ & Sederhana \\
$0.7<0.8$ & Baik \\
$0.8<0.9$ & Sangat Baik \\
0.9 & Terbaik \\
\hline
\end{tabular}


Jadual 2 menunjukkan keputusan ujian kebolehpercayaan kajian rintis ketahanan mental dan jadual 3 untuk kecerdasan emosi.

Jadual 2:Keputusan ujian kebolehpercayaan kajian rintis bagi ketahanan mental

\begin{tabular}{cccc}
\hline Dimensi & Bilangan Item & Jumlah Sampel & Nilai Alpha \\
\hline Keyakinan & 7 & 30 & .701 \\
Komitmen & 7 & 30 & .678 \\
Kawalan Diri & 7 & 30 & .689 \\
Cabaran & 7 & 30 & .621 \\
\hline
\end{tabular}

Jadual 3:Keputusan ujian kebolehpercayaan kajian rintis bagi kecerdasan emosi

\begin{tabular}{cccc}
\hline Dimensi & Bilangan Item & Jumlah Sampel & Nilai Alpha \\
\hline Persepsi Emosi & 4 & 30 & .755 \\
Penggunaan Emosi & 3 & 30 & .616 \\
Kefahaman Emosi & 4 & 30 & .627 \\
Pengurusan Emosi & 8 & 30 & .756 \\
\hline
\end{tabular}

Kajian rintis dilakukan dengan mengedarkan borang soal selidik kepada 30 atlet yang bukan responden sebenar kajian. Ujian kajian rintis bagi ketahanan mental menunjukkan nilai kebolehpercayaan alfa Cronbach adalah .70 dan kecerdasan emosi adalah .71. Dengan ini, kesemua konstruk untuk ketahanan mental dan kecerdasan emosi sesuai digunakan dalam kajian kerana mempunyai nilai kebolehpercayaan yang baik.

\section{DAPATAN KAJIAN}

\section{Objektif kajian 1: Mengenal pasti tahap ketahanan mental dan kecerdasan emosi dalam kalangan atlet berpasukan dan individu.}

Bagi mengenal pasti tahap ketahanan mental dan kecerdasan emosi, data telah dianalisis secara deskriptif. Jadual 4 menunjukkan dimensi keyakinan diri mempunyai nilai $\min (\min =3.76, \mathrm{SP}=0.26)$ berada pada tahap yang tinggi diikuti oleh dimensi cabaran, kawalan diri dan komitmen. Secara keseluruhan skor ketahanan mental $(\min =3.49, \mathrm{SP}=0.16)$ dalam kalangan atlet berpasukan dan individu berada pada tahap yang sederhana.

Jadual 4:Analisis deskriptif tahap ketahanan mental atlet berpasukan dan individu

\begin{tabular}{lccc}
\hline & Min & Sisihan Piawai & Tahap \\
\hline Keyakinan Diri & 3.76 & 0.26 & Tinggi \\
Komitmen & 3.01 & 0.27 & Sederhana \\
Cabaran & 3.64 & 0.32 & Sederhana \\
Kawalan Diri & 3.55 & 0.35 & Sederhana \\
\hline Keseluruhan (Ketahanan Mental) & $\mathbf{3 . 4 9}$ & $\mathbf{0 . 1 6}$ & Sederhana \\
\hline (Tahap: Rendah $=1.00-2.33$, Sederhana $=2.34-3.66$, Tinggi $=3.67-5.00)$ &
\end{tabular}

Manakala jadual 5 menunjukkan dimensi pengurusan emosi adalah tinggi $(\min =3.73, \mathrm{SP}=$ 0.31 ) diikuti oleh dimensi persepsi emosi, penggunaan emosi, dan kefahaman emosi. Secara keseluruhannya tahap kecerdasan emosi juga berada pada tahap yang sederhana dengan skor kecerdasan emosi $(\min =3.37, \mathrm{SP}=0.21)$ 
Jadual 5:Analisis deskriptif tahap kecerdasan emosi atlet berpasukan dan individu

\begin{tabular}{lccc}
\hline & Min & Sisihan Piawai & Tahap \\
\hline Persepsi Emosi & 3.65 & 0.45 & Sederhana \\
Penggunaan Emosi & 3.46 & 0.42 & Sederhana \\
Kefahaman Emosi & 2.64 & 0.37 & Sederhana \\
Pengurusan Emosi & 3.73 & 0.31 & Tinggi \\
\hline Keseluruhan $($ Kecerdasan Emosi) & $\mathbf{3 . 3 7}$ & $\mathbf{0 . 2 1}$ & Sederhana \\
\hline (Tahap: Rendah $=1.00-2.33$, Sederhana $=2.34-3.66$, Tinggi $=3.67-5.00)$ &
\end{tabular}

Objektif kajian 2: Mengenal pasti hubungan antara tahap ketahanan mental dan kecerdasan emosi dalam kalangan atlet berpasukan dan individu.

Jadual 6:Pekali korelasi antara ketahanan mental dan kecerdasan emosi dalam kalangan atlet berpasukan

\begin{tabular}{lccl}
\hline Hubungan & \multicolumn{2}{l}{ Ketahanan Mental } & Interpretasi \\
\cline { 2 - 3 } & $\mathrm{r}$ & Sig. & \\
\hline Kecerdasan Emosi & .245 & .157 & Sangat lemah \\
\hline
\end{tabular}

Analisis korelasi Pearson daripada jadual 6 menunjukkan tidak terdapat hubungan yang signifikan antara ketahanan mental dan kecerdasan emosi dalam kalangan atlet berpasukan dengan nilai $\mathrm{r}=0.245$ dan $\mathrm{sig}=0.157(\mathrm{p}>0.05)$. Hasil analisis menunjukkan kekuatan hubungan antara ketahanan mental dan kecerdasan emosi dalam kalangan atlet berpasukan adalah sangat lemah. Justeru itu, dapatan ini bermaksud ketahanan mental tidak mempengaruhi kecerdasan emosi dalam kalangan atlet berpasukan secara keseluruhannya.

Jadual 7:Pekali korelasi antara ketahanan mental dan kecerdasan emosi dalam kalangan atlet individu

\begin{tabular}{lccl}
\hline Hubungan & \multicolumn{2}{c}{ Ketahanan Mental } & Interpretasi \\
\cline { 2 - 3 } & $\mathrm{r}$ & Sig. & \\
\hline Kecerdasan Emosi & .623 & .017 & Sederhana \\
\hline
\end{tabular}

Jadual 7 menunjukkan analisis korelasi Pearson terdapat hubungan yang signifikan antara ketahanan mental dan kecerdasan emosi dalam kalangan atlet individu dengan nilai $\mathrm{r}=0.623 \mathrm{dan} \mathrm{sig}=0.017$ $(\mathrm{p}<0.05)$. Hasil analisis menunjukkan walaupun kekuatan hubungan antara ketahanan mental dan kecerdasan emosi dalam kalangan atlet berpasukan adalah sederhana, namun terdapat hubungan yang signifikan antara ketahanan mental dan kecerdasan emosi. Justeru itu, dapatan ini bermaksud ketahanan mental mempengaruhi kecerdasan emosi dalam kalangan atlet individu secara keseluruhannya.

\section{PERBINCANGAN}

Dapatan kajian yang diperolehi daripada analisis deskriptif terhadap dimensi dalam konstruk ketahanan mental dan kecerdasan emosi menunjukkan dimensi keyakinan diri dan pengurusan emosi menunjukkan min tertinggi. Persoalan kajian yang pertama menunjukkan majoriti atlet bersetuju bahawa keyakinan diri mempengaruhi kepada ketahanan mental dan pengurusan emosi mempengaruhi kecerdasan emosi mereka. Keyakinan diri yang tinggi dilihat mampu meningkatkan tahap ketahanan mental atlet sebelum, semasa dan selepas pertandingan. Penyataan ini disokong oleh kajian daripada Meggs, Ditzfeld dan Golby (2014) yang menyatakan bahawa atlet yang mempunyai keyakinan diri yang tinggi dapat meningkatkan ketahanan mental dan memperbaiki kelemahan diri serta prestasinya dari semasa ke semasa. Satu kajian telah dijalankan oleh Mohd Sofian, Yudha, Norinda, Zeinab, Mohd 
Nizam dan Mastura (2012) kepada atlet bola sepak dan mendapati bahawa hasil kajian menunjukkan prestasi atlet berkait rapat dengan keyakinan diri dalam meningkatkan ketahanan mental ketika perlawanan yang mengambil masa yang lama. Sebaliknya, atlet yang mempunyai rendah keyakinan diri lebih cenderung untuk melakukan kesilapan dan sering gugup serta mudah tertekan untuk menghadapi pihak lawan.

Seterusnya, dimensi pengurusan emosi yang baik dapat dilihat untuk meningkatkan prestasi atlet dan mengurangkan unsur negatif ketika perlawanan atau latihan. Selari dengan kajian daripada Cowden (2016) yang menyatakan pengurusan emosi adalah dimensi yang utama kerana atlet akan mempunyai keupayaan untuk memahami dan menguruskan emosi lawan dengan mengubah strategi perlawanan untuk menganggu emosi pihak lawan. Dengan ini atlet akan mempunyai keupayaan untuk memahami dan menguruskan perasaan sendiri dan bijak dalam membuat keputusan dengan rasional. Sehubungan dengan itu, pengurusan emosi yang baik boleh meningkatkan prestasi atlet. Kenyataan ini disokong oleh Chan dan Mallett (2011) dan Jordan dan Troth (2004) yang menyatakan bahawa pengurusan emosi yang positif dapat mengawal emosi atlet dengan baik dan mampu untuk mempengaruhi emosi orang lain. Kajian daripada Chan dan Mallett (2011) menyatakan bahawa dengan mempunyai pengurusan emosi yang betul, atlet lebih terbuka untuk membuat keputusan dan mampu mengawal emosi walaupun berada dalam situasi yang tegang ketika pertandingan. Dengan mempunyai pengurusan emosi yang tinggi, atlet mampu untuk mengatasi dan berjaya menangani emosi mereka semasa persaingan.

Persoalan kajian yang terakhir menunjukkan tidak terdapat perbezaan yang signifikan antara ketahanan mental dan kecerdasan emosi dalam kalangan atlet berpasukan UKM. Dapatan ini selari dengan Nicholls, Polman, Levy dan Backhouse (2009) menyatakan atlet berpasukan mempunyai faktor lain yang mungkin mempengaruhi tahap ketahanan mental dan kecerdasan emosi dalam mencapai pencapaian yang optimum seperti teknik yang baru, latihan yang lebih kerap atau sokongan daripada keluarga. Dengan ini, faktor tersebut mungkin merangsang dalam membantu mereka untuk lebih yakin dalam mencapai kejayaan berbanding mempunyai tahap ketahanan mental dan kecerdasan emosi yang tinggi. Manakala dapatan kajian menunjukkan terdapat hubungan yang signifikan antara ketahanan mental dan kecerdasan emosi dalam kalangan atlet individu UKM. Dapatan ini disokong oleh kajian oleh Cowden (2016), kecerdasan emosi merupakan peranan penting dalam ketahanan mental atlet individu. Hal demikian kerana atlet lebih bekerja keras ketika pertandingan berbanding atlet berpasukan. Beliau berpendapat ketahanan mental dan kecerdasan emosi juga mempengaruhi prestasi atlet secara fizikal, taktikal dan psikologi. Dengan mempunyai ketahanan mental dan kecerdasan emosi yang baik, atlet individu dapat mengatasi pelbagai cabaran dengan berkeyakinan walaupun berada dalam keadaan yang sukar dan dapat meningkatkan keberkesanan diri mereka (self-efficacy) (Mahoney, Ntoumanis, Gucciardi, Mallett \& Stebbings, 2015).

Seterusnya, penemuan kajian ini mendapati bahawa hubungan ketahanan mental dan kecerdasan emosi tidak mempengaruhi atlet berpasukan tetapi mempengaruhi atlet individu. Perkara ini adalah disebabkan oleh atlet individu perlu menghadapi pihak lawan secara bersendirian berbanding atlet berpasukan. Kenyataan ini disokong oleh Kajbafnezhad et al. (2011) yang menyatakan bahawa atlet individu bergantung kepada kebolehan mereka berbanding atlet berpasukan bergantung kepada prestasi rakan sepasukan. Atlet berpasukan menghabiskan banyak latihan berlatih dengan rakan sebaya dan lebih banyak menghabiskan masa berinteraksi. Manakala atlet individu lebih banyak menghabiskan masa untuk berlatih sahaja. Kajian tersebut juga menunjukkan atlet individu lebih banyak masa untuk menumpukan kepada kemahiran psikologi dalam meningkatkan ketahanan mental dan kecerdasan emosi. Hal ini demikian kerana atlet individu sering berada dalam persekitaran yang tenang dan kurang hilang tumpuan berbanding atlet berpasukan.

Justeru itu, penemuan kajian ini mendapati bahawa hubungan ketahanan mental dan kecerdasan emosi tidak mempengaruhi atlet berpasukan tetapi mempengaruhi atlet individu. Perkara ini adalah disebabkan oleh atlet individu perlu menghadapi pihak lawan secara bersendirian berbanding atlet berpasukan. Kenyataan ini disokong oleh Kajbafnezhad et al. (2011) menyatakan bahawa atlet individu bergantung kepada kebolehan mereka berbanding atlet berpasukan bergantung kepada prestasi rakan sepasukan. Atlet berpasukan menghabiskan banyak masa latihan berlatih dengan rakan sebaya dan lebih banyak menghabiskan masa berinteraksi. Manakala atlet individu lebih banyak menghabiskan masa untuk berlatih sahaja. Kajian tersebut juga menunjukkan atlet individu lebih banyak masa untuk 
menumpukan kepada kemahiran psikologi dalam meningkatkan ketahanan mental dan kecerdasan emosi. Hal ini demikian kerana atlet individu sering berada dalam persekitaran yang tenang dan kurang hilang tumpuan berbanding atlet berpasukan.

\section{KESIMPULAN}

Secara keseluruhannya, tahap ketahanan mental dan kecerdasan emosi mempengaruhi atlet berpasukan dan individu dalam meningkatkan prestasi dan mencapai kejayaan. Kajian ini mendapati konstruk keyakinan diri yang paling menyumbang antara keempat-empat konstruk ketahanan mental. Selain itu, konstruk pengurusan emosi merupakan konstruk paling menyumbang bagi kecerdasan emosi. Dengan mempunyai pengurusan emosi yang baik, atlet mudah menerima arahan dan bijak dalam menguruskan emosi ketika berhadapan dengan pihak lawan.

Oleh yang demikian, pihak Universiti perlu memberi perhatian dan penekanan kepada pembangunan kemahiran ketahanan mental dan kecerdasan emosi dalam kalangan atlet. Hal ini demikian kerana pihak Universiti akan dapat mengekalkan peningkatan prestasi atlet dengan mempunyai keyakinan diri yang tinggi untuk menghadapi setiap cabaran dan pengurusan emosi yang baik ketika menghadapi pihak lawan. Justeru itu, keyakinan diri dan pengurusan emosi yang tinggi boleh mempengaruhi prestasi atlet berpasukan dan individu serta dapat membantu dan dijadikan rujukan kepada pihak universiti, jurulatih, ahli psikologi atau organisasi yang terlibat bagi atlet itu sendiri.

\section{RUJUKAN}

Brackett, M. A., Rivers, S. E., Shiffman, S., Lerner, N. \& Salovey, P (2006). Relating emotional abilities to social functioning: a comparison of self-report and performance measures of emotional intelligence. J Pers Soc Psychology 91(4): 780-795.

Bull, S. J., Shambrook, C. J., James, W., \& Brooks, J. K (2005). Towards an understanding of mental toughness in elite english cricketers. Journal of Applied Sport Psychology, 17(3), 209-227.

Cashmore, E (2002). Sport Psychology: The Key Concepts. London: Routledge.

Chan, J. T. \& Mallett, C. J (2011). The value of emotional intelligence for high performance coaching. International Journal of Sports Science \& Coaching, 6(3).

Clough, P. J., Earle, K., \& Sewell, D (2002). Mental toughness: the concept and its measurement. In I. Cockerill. Solutions in Sport Psychology (pp. 32-43). London: Thomson

Coulter T. J., Mallett C., \& Gucciardi D. F (2010). Understanding mental toughness in australian soccer: perceptions of players, parents and coaches. Journal of Sport Sciences, 28(7). 699-716.

Cowden,R.G (2016). Mental toughness, emotional intelligence, and coping effectiveness: an analysis of construct interrelatedness among high-performing adolescent male athletes. Percept Motor Skills, 123(3): 737753.

Darvishi, S., Marati, A. \& Amirpour, B. (2015). Effectiveness of emotional intelligence on mood profle in female student athletes. Social Development \& Health Promotion Research Center, 5(1).

Fiori, M., Antonietti, J. P., Mikolajczak, M., Luminet, O., Hansenne, M. \& Rossier, J. (2014). What Is the Ability Emotional Intelligence Test (Msceit) Good For? An Evaluation Using Item Response Theory. PLoS One, 9(6): e98827.

Fridlund Dunton, G., Schneider, M., J. Graham, D. \& Cooper, D. (2006). Physical Activity, Fitness, and Physical Self-Concept in Adolescent Females. 18.

Fruchart, E., \& Rulence-Paques, P. (2014) Condoning aggressive behaviour in sport: A comparison between professional handball players, amateur players, and lay people. Psicológica, 35, 585-600.

Goleman, D (1995). Emotional intelligence. New York: Bantam Books

Gould, D., Dieffenbach, K., \& Moffett, A (2012). Psychological talent and its development in Olympic champions. Journal of Applied Sport Psychology, 14, 177-210.

Hany Mahmoud Abou-Bakri \& Mostafa, M. E.-S. (2016). The impact of mental toughness training on speed and accuracy of some offensive skills of field hockey junior players. Journal of Applied Sports Science September, 6(3). 
Hashim, B. (2007). Orientasi matlamat dan kecenderungan keagresifan instrumental di kalangan pemain bola baling remaja. Doctoral dissertation, Universiti Pendidikan Sultan Idris.

Institut Sukan Negara Malaysia (2015). Apa Itu 'Psikologi' Sukan. Diakses daripada http://isn.gov.my

Jackson, S.L (2003) Research Methods and Statistics: A Critical Thinking Approach. USA: Thomson Learning.

Jordan, P.J. and Troth, A.C. (2004) Managing emotions during team problem solving: emotional intelligence and conflict resolution, Human Performance, 17, 195-218.

Kajbafnezhad, H., Ahadi, H., Heidarie, A. R., Askari, P., \& Enayati, M. (2011). Difference between team and individual sports with respect to psychological skills, overall emotional intelligence and athletic success motivation in Shiraz city athletes. Journal of Basic and Applied Scientific Research, 1(11), 1904-1909.

Kobasa, S. C. (1979). Stressful life events, personality, and health - Inquiry into hardiness. Journal of Personality and Social Psychology, 37, 1-11.

Krane, V., \& Williams, J. M. (2006). Psychological characteristics of peak performance. In J.

M.Williams (Ed.), Applied sport psychology: Personal growth to peak performance (5th ed., pp. 207227). Boston, MA: McGraw-Hill

Krishnaveni, K., \& Shahin, A. (2014). Aggression and its influence on sports performance. International Journal of Physical Education, Sports, and Health, 1(2), 29-32.

Lane, A. M., Thelwell, R. C., Lowther, J. \& Devonport, T. J. (2009). Emotional intelligence and psychological skills use among athletes. Social Behavior and Personality: an International Journal, 37(2): 195-201.

Mahoney, J. W., Ntoumanis, N., Gucciardi, D. F., Mallett, C. J. \& Stebbings, J. (2015). Implementing an autonomy-supportive intervention to develop mental toughness in adolescent rowers. Journal of Applied Sport Psychology, 28(2), 199-215.

Mahoney, J. W., Gucciardi, D. F., Ntoumanis, N. \& Mallett, C. J. (2014). Mental toughness in sport: motivational antecedents and associations with performance and psychological health. J Sport Exerc Psychol, 36(3): 281-292.

Mayer, J. D., Salovey, P. \& Caruso, D. R. (2002). Emotional intelligence: new ability or eclectic traits? $A m$ Psychol 63(6): 503-517.

Meggs, J., Ditzfeld, C., dan Golby, J. (2014). Self-concept organisation and mental toughness in sport. Journal of Sports Sciences, 32, 101-109.

Middleton, S. C., Marsh, H. W., Martin, A. J., Richards, G. E., dan Clark Perry, E. (2005). Discovering mental toughness: a qualitative study of mental toughness in elite athletes [R], SELF Research Centre, University of Western Sydney, Australia.

Mohd. Majid Konting. (2005). Kaedah Penyelidikan Pendidikan Dewan Bahasa dan Pustaka Kuala Lumpur. Dawama Sdn. Bhd, Kompleks Dawama, Selangor Darul Ehsan.

Mohd Sofian, O. F., Yudha, H. S., Norinda, S., Zeinab, G., Mohd Nizam, A. \& Mastura J. (2012). Mental toughness among footballers: A case study. International Journal of Academic Research in Business and Social Sciences. Vol. 2, No. 1.

Mullet, E., Sorum, P. C., Teysseire, N., Nann, S., Martinez, G. E. M., Kamblef, R. A. S., Olivari, C., \& Munoz Sastre, M. T. (2012). Functional measurement in the field of empirical bioethics. Psicológica, 33, 665681.

Neil, R., Hanton, S., Mellalieu, S.D. and Fletcher, D. (2011). Competition stress and emotions in sport performers: The role of further appraisals. Psychology of Sport and Exercise, 12(4), pp.460-470.

Nicholls, A. R., Polman, R. C. J., Levy, A. R. \& Backhouse, S. H. (2009). Mental toughness in sport: achievement level, gender, age, experience, and sport type differences. Personality and Individual Differences, 47(1): 73-75.

Nur Dalilah. D. (2016). Hubungan kekuatan mental dan prestasi akademik atlet bola sepak universiti kebangsaan malaysia (UKM). Jurnal Sains Sukan \& Pendidikan Jasmani 6, No. 1, 2017, 21 to 35.

Ranjbar, S., Gharayagh Zandi, H., \& Fatemi, S. (2018). Mindfulness, emotional intelligence and mental toughness in successful and unsuccessful karate athletes in Iran men's karate super league. Journal of Motor Learning and Movement, 10(2), 173-193.

Sit, C.H.P., Lindner, K.J. (2005). Motivational orientations in youth sport participation using achievement goal theory and reversal theory. Personality \& Individual Difference, 38: 605- 18

Zaid, R. H. R. (2017). Masalah disiplin, S.Komalam digugurkan dari Sukan SEA KL 2017. Retrieved from http://www.astroawani.com/berita-sukan/masalah-disiplin-s-komalam-digugurkan-dari-sukan-sea-kl2017-151840 
Jurnal Sains Sukan dan Pendidikan Jasmani, Vol 8 No 2, 2019 (8-18)

ISSN: 2232-1918 / eISSN: 2600-9323

https://ejournal.upsi.edu.my/journal/JSSPJ

‡ Nurnadhira Binti Nazri

Fakulti Pendidikan

Universiti Kebangsaan Malaysia

Malaysia

Email: adranazri@gmail.com 